\title{
Experimental assessment of a wireless communications platform for the built and natural heritage
}

\author{
M.I. Martínez-Garrido a,b,c, ${ }^{\text {, R. Fort }}{ }^{\text {a,b }}$ \\ ${ }^{a}$ Instituto de Geociencias IGEO (CSIC, UCM), C/José Antonio Nováis 12, 28040 Madrid, Spain \\ ${ }^{\mathrm{b}}$ CEI - Moncloa, UCM-UPM, CSIC, Madrid, Spain \\ ${ }^{\mathrm{c}}$ Department of Telematic Engineering and Electronic, School of Telecommunications Engineering, ETSIST, Technical University of Madrid, Spain
}

a b s tra ct

Wireless sensor networks have become extremely popular in a number of fields in recent years, the cultural heritage among them. To date, however, communications quality has not been technically validated in any of the various built (churches, museums, archaeolog- ical sites) or natural (caves, lava tubes) heritage scenarios. The present study establishes methodology for assessing the quality of wireless communications and validating the net- work used, both of which are essential to guaranteeing accurate long-term monitoring in heritage scenarios. Parameters such as signal strength, link quality, range and success rate were analysed with a view to preventing transmission failure and ensuring reliable mon- itoring for the preventive conservation of the cultural heritage.

\section{Introduction}

Thanks to their low energy demand and price and ready integration with other technologies [1], wireless sensor networks (WSN) have been used in a wide range of scenarios, including automobiles [2,3], roads [4], earth assets [5], medicine [6,7], home monitoring systems [8], construction and the environment [9], and structural monitoring [10]. Nonetheless, no stable wireless communications system has been put forward to date for comprehensively and reliably monitoring decay in built and natural heritage scenarios. Nor has any method been developed for assessing communications in these domains that would be general enough to be applicable to others. WSN cultural heritage monitoring conducted to date has addressed a variety of factors, including comfort or environmental conditions [11,12], microclimate [13] and inner wall temperature

\footnotetext{
介 Corresponding author at: C/José Antonio Nováis 12, 28040 Madrid, Spain. Tel.: +34 913945235; fax: +34915442535.

E-mail addresses: mi.martinez.garrido@csic.es (M.I. Martínez-Garrido), rafael.fort@csic.es (R. Fort).
}

and humidity, in which external agents such as solar radiation are taken into consideration [8]. The quality of the communications in these scenarios has not been validated, however, in heritage buildings, natural assests [14] or archaeological sites [15]. Robust and efficient monitoring with these technologies is instrumental to establishing the causes of heritage element decay, which may include solar radiation, salt crystallisation, leaks or condensation, vibration and air pollution. Moreover, the preventive conservation of the cultural heritage presently advocated [16-19] calls for the uninterrupted, long-term monitoring of many parameters, in which the exhaustive assessment of network communications is an imperative. The present paper introduces a pioneering assessment of WSN communications in a number of built and natural heritage scenarios based on parameters such as the position of wireless sensor network nodes with respect to obstacles, the distance to the base station and weather conditions with a view to validating the system and establishing a methodology for ensuring reliable communications links for cultural asset 
Consequently, that methodology, based on measuring communications quality-related parameters, was used to quantify the suitability of the installation under the conditions studied (type of obstacles, distances, data acquisition rate...) in a number of heritage scenarios. Despite the particulars characterising each heritage monitoring campaign, the assessment of these parameters and the respective findings can be used to define deployment and assessment guidelines for future long-term monitoring campaigns.

\section{Methodology}

The scenarios monitored in the present study were selected on the grounds of their impact on the cultural heritage. A number of built heritage scenarios (churches and museums) were selected in a first stage with a view to establishing an initial understanding of the performance of the wireless sensor network system in indoor environments. The results were then applied to test its operation in more aggressive outdoor environments such as archaeological sites. Altogether, the experimental assessments covered two churches, San Juan Bautista at Talamanca de Jarama, Madrid, Spain, and Santo Domingo de Silos, Pinto, Spain; an archaeological site and museum (Complutum) at Alcalá de Henares, Madrid, Spain; Neolithic caves (El Risco de las Cuevas) at Perales de Tajuña, Madrid, Spain; and the Jameos del Agua lava tube at Lanzarote, Las Palmas, Spain. Most of these monuments are listed cultural heritage assets, while the archaeological remains at Alcalá de Henares also comprise a UNESCO World Heritage Site. Communications quality was assessed in all these scenarios, measuring signal and link parameters for Smartmote sensors [20] both indoors (churches and archaeological museum of different dimensions and construction characteristics) and out (caves, lava tubes), under varying terrain conditions, distances and pedestrian flows. In the churches, congregations were present on the occasion of religious rites, which were less frequent in the smaller rural church. The archaeological museum is a more recent structure. In addition to visitors, it has a restoration workshop and materials storage that generate human traffic. Although the caves are visited much less intensely, they are occasionally frequented due to the sports and recreational activities available in the surrounds. In contrast, tourist traffic is intense all day long in the lava tube, which also has a restaurant and offers evening entertainment.

The degree of obstruction by obstacles between the emitter and receiver was assessed bearing in mind their characteristics and position with respect to the Fresnel zones [21,22]. Calculations were performed using the distances between transmitter and receiver (assuming obstacle at the midpoint), in which the first Fresnel zone radius was defined as follows:

$$
\begin{aligned}
& S \\
& r_{1} 1 / 48: 657 \quad \frac{D}{f}
\end{aligned}
$$

where $r_{1}$ is the radius in metres (m), $D$ the distance in kilometres $(\mathrm{km})$ and $\mathrm{f}$ transmission frequency in gigahertz $(\mathrm{GHz})$. The drawing in Fig. 1 illustrates partial and total Fresnel zone obstruction.

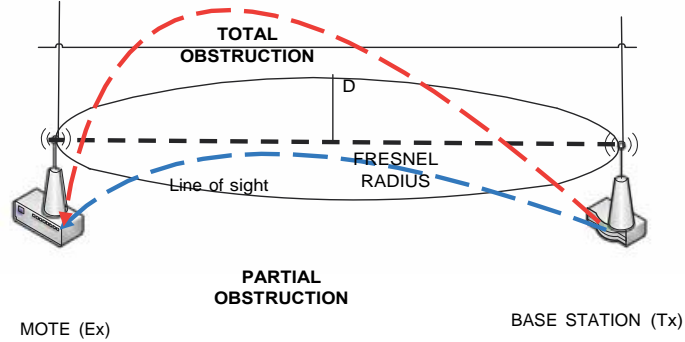

Fig. 1. Partial and total obstruction of the Fresnel radius between emitter (Ex) and receiver (Tx)

The assumption adopted in this study was that to avoid losses, $60 \%$ of the radius of the first Fresnel radius (clearance zone) would have to be obstacle-free.

Other conditions, such as data acquisition rates and the presence of antenna extensions where required, were likewise tested to ascertain their effect on the findings and battery consumption (difference between initial and final voltage).

Both the RSSI (received signal strength indicator) and correlation (CORR) values were monitored in the frames received as described in item 2.2. below. The percentage (\%) of successfully received and of duplicated messages were found in all cases.

\subsection{WSN platform characteristics}

The wireless sensor platform used for the present study comprised a network of Smartmote sensor nodes fitted with a Texas Instruments CC2520 radio transceiver for wireless communication in the 2.4-GHz ISM band, and a Texas Instruments CC2090 output amplifier. Sensor nodes or motes were positioned in each of the scenarios monitored. The information gathered by their sensors was sent to a base station or sink, where it was stored in a database. The system was designed to automatically detect new motes and integrate the respective data. The motes performed standard functions such as data conveyance and processing [23], as shown in Fig. 2.

Each mote was fitted with an ultra-low (a few 1A) energy microcontroller to lengthen the service life of the 2.6 V, 7.7 AH lithium batteries and a series of LED status indicators (green for data reception, flashing red for logging). CTP tree topology was used in the network architecture [24-26]. The base station consisted of a physical sensor node platform and a low-cost Raspberry PI or single board computer (SBC). Running on a Linux operating system (distributed by Debian), it was fitted with WLAN connectivity and wifi access for remote real-time monitoring via a PHP web application that also delivered downloadable .csv format files for subsequent data processing. The sensor nodes were enclosed in cases affording IP65 protection against water and dust ingress, apt for operating at temperatures of 25 to $85 \mathrm{C}$. This robust encapsulation was suitable for indoor heritage monitoring as well as for outdoor conditions such as prevailing in archaeological sites or caves, characterised by aggressive or highly polluted environments. Low power Sensiron SHT25 sensors 


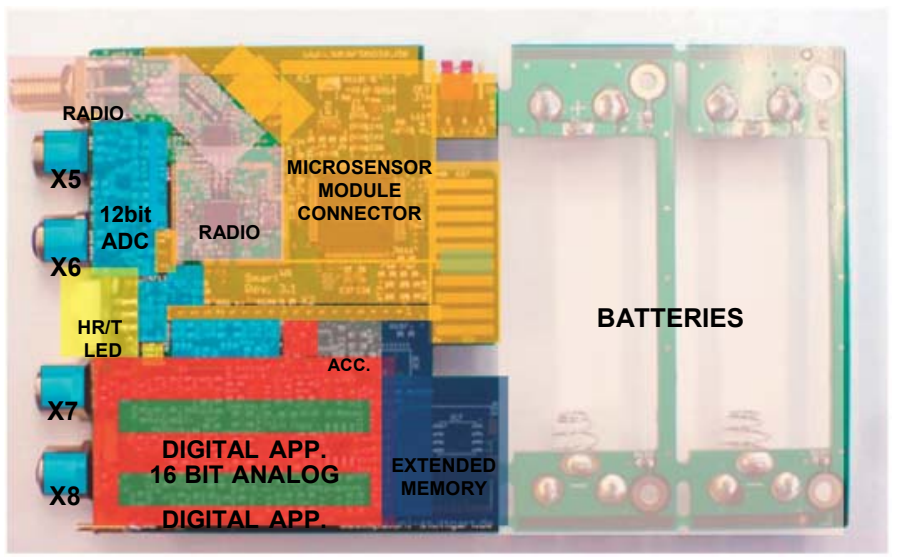

Fig. 2. SMOOHS (Smart Monitoring of Historic Structures) processor motherboard showing mounted sensor connectors and functional areas [23]
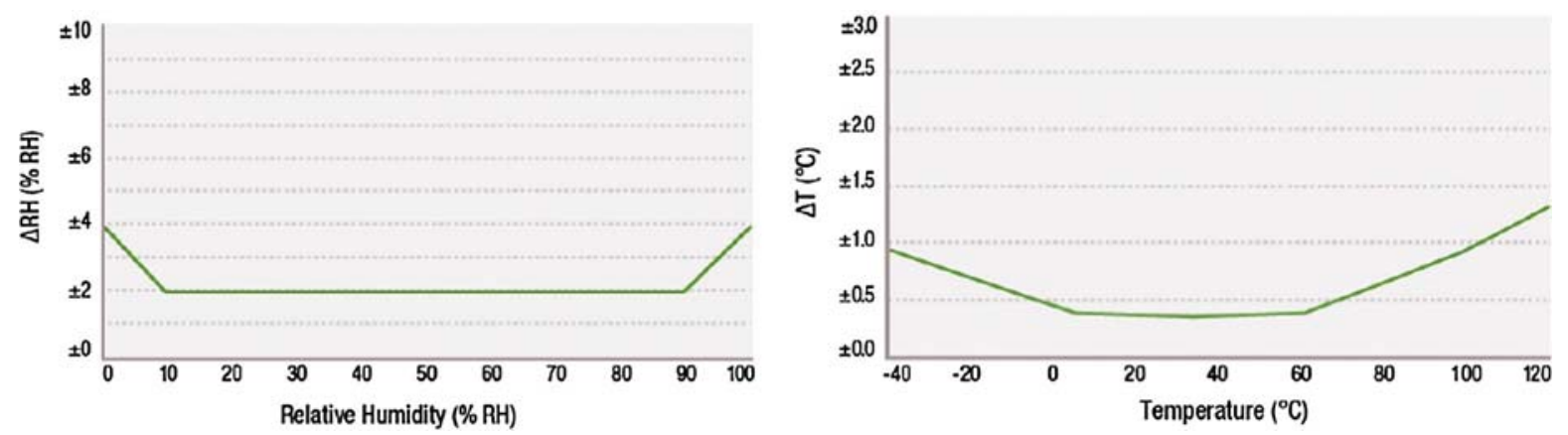

Fig. 3. Relative humidity (HR\%) and temperature ( $\mathrm{T}$ C) precision for Sensiron SHT25 sensors [27].

[27] were used to measure relative humidity and temperature (four sensors connected via four 12C mote inlets/outlets), with operating ranges of $0-100 \%$ for relative humidity and 40 to +125 C for temperature. Sensor precision is plotted against temperature and relative humidity in Fig. 3a and b.

The temperature and relative humidity sensors used as controls in this study, fitted with sintered HD polyethylene-coated E + E Elektronik Ges m.b.H series EE00 sensing probes, were designed to deliver accurate measurements under highly demanding humidity conditions with no electronics outages and speedy sensor recovery after exposure to $>95 \%$ relative humidity.

\subsection{Communications quality parameters}

The network was fitted with communications quality measuring apparatus. Further to the link quality criteria set out in IEEE 802.15.4 [28], the parameters measured in each sensor node included RSSI (received signal strength indicator) [29] and radio transceiver correlation values [30]. Dipole omni antennae with a vertical linear polarisation gain of $2 \mathrm{dBi}$, a frequency of $2.4-2.5 \mathrm{GHz}$, a standing wave ratio (SWR) of $61.5: 1$ and impedance of $50 \mathrm{X}$ were used throughout. These $105 \quad 10 \quad 10-\mathrm{mm}\left(\begin{array}{lll}\mathrm{H} & \mathrm{W} & \mathrm{D})\end{array}\right.$ antennae were equipped with SMA (subminiature version A) connectors.

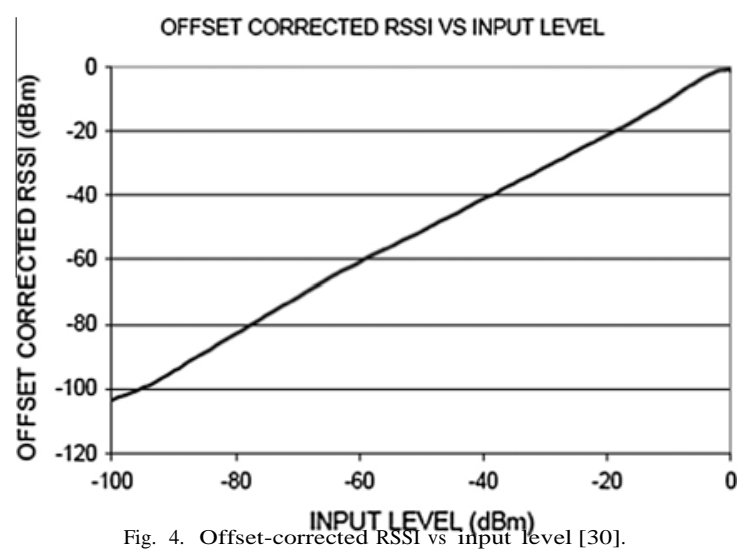

Fig. 4 [30] plots the input level against the offsetcorrected RSSI. The RSSI range measured was $100 \mathrm{~dB}$ with a precision of $4 \mathrm{~dB}$.

Moreover, while the radio transceiver provided no LQI (Link Quality Indicator) directly, an indication of link quality could be obtained for each installation as a measure of the strength or quality of the frame received. Further to the definition in standard IEEE 802.15.4 [28], LQI is directly 
Table 1

Communications quality assessment parameters for San Juan Bautista Church at Talamanca de Jarama, Madrid, Spain.

\begin{tabular}{|c|c|c|c|c|}
\hline $\begin{array}{l}\text { Parameter measured and } \\
\text { transmitted }\end{array}$ & Category & Objective & Minimum value & Maximum value \\
\hline $\mathrm{T}(\mathrm{C})$ & Sensor & $\mathrm{T}$ measurements & $40 \mathrm{C}$ & $+125 \mathrm{C}$ \\
\hline HR (\%) & Sensor & RH measurements & $0 \%$ & $100 \%$ \\
\hline RSSI (dBm) & Communications & Incoming signal strength & $\begin{array}{l}100 \mathrm{dBm} \text { (RSSI > } 40 \mathrm{dBm} \\
\text { excellent signal) }\end{array}$ & $\begin{array}{l}\text { OdBm }(\mathrm{RSSI}>40 \mathrm{dBm} \\
\text { excellent signal) }\end{array}$ \\
\hline CORR (dimensionless) & Communications & $\begin{array}{l}\text { Quantitative measure of link } \\
\text { quality }\end{array}$ & 50 (minimum perceptible) & 110 (excellent quality) \\
\hline Battery strength (V) & $\begin{array}{l}\text { Power } \\
\text { consumed }\end{array}$ & Battery strength & $\begin{array}{l}0 \\
\text { Consumption was computed } \\
\text { the beginning and end of the }\end{array}$ & $\begin{array}{l}3.6 \\
\text { difference in battery voltage at } \\
\text { aign }\end{array}$ \\
\hline
\end{tabular}

proportional to the mean correlation value (CORR) calculated for the first eight symbols following the SFD (start of frame delimiter) for each incoming frame and to indices based on empirical packet error rate (PER) measurements $[28,30]$. Consequently, CORR can be used as an indirect measure of link quality. A correlation value of around 110 is indicative of a high quality frame, whereas a value of approximately 50 is typically associated with the lowest quality frame detectable by a radio transceiver [30].

Since the data were transmitted with pre-set error correction bits, a certain amount of noise- or interferenceinduced randomisation could be accommodated, although at the expense of a lower correlation value.

Higher values for RSSI and CORR both denote better communication results. Link range, obstructive materials and their position in the line of sight, i.e., the existence of an unobstructed (LoS) or partially or totally obstructed (NLoS) line of sight, the success rate and the percentage of duplicated messages received were also analysed.

The parameters measured and transmitted over the network can be divided into two main categories: on the one hand, the readings taken by the sensors themselves (in this study temperature and relative humidity), and on the other communications quality and energy demand. The latter quantified the effect of obstacles in the path between the mote and the base station (CORR), the strength of the signal received (RSSI) and the energy consumed by the motes, measured in terms of battery strength. Based on the findings, other parameters of interest were calculated, such as message repetition and success rates compared to the data acquisition rate predetermined for the network, as shown for each installation. Table 1 lists the parameters measured in this study.

\section{Results}

This section describes the monitoring campaigns conducted to assess communications quality in both indoor and outdoor environments with different link ranges and characteristics, including the built (two churches of different sizes, a museum and an archaeological site) and natural (caves and lava tube) heritage. The assessment periods ranged from 13 to 34 days, depending on site accessibility and permits.

\subsection{Built heritage}

3.1.1. San Juan Bautista Church at Talamanca de Jarama, Madrid, Spain

This $36.50 \quad 12.70 \quad 10.50-m$ Romanesque building, located at Talamanca de Jarama, Madrid, Spain (40 $44^{\circ} \mathrm{N}$, $330^{\circ} \mathrm{W}$ ), traces its origin back to the twelfth-thirteenth centuries, when its dolostone apse (still standing) was erected [31]. Its heating system [16,31] and exposure to solar radiation [9], together with the damp- and saltinduced decay detected in the church $[9,16]$, were regarded as decisive factors when positioning the network nodes. The church was reconstructed and remodelled on a number of occasions through the nineteenth century. Its present nave and side aisles have a Mudejar-style wood ceiling. The temple's Baroque bell tower was built in the seventeenth-eighteenth centuries. The installation in this church is depicted in Fig. 5.

The data acquisition rate in this network was every $5 \mathrm{~min}$ for all the motes, which were in place for 13 days, from 18 to 30 September 2013.

The findings are given in Table 2 .

The lowest RSSIs were recorded for motes 4, 5 and 1 , with values of $17.10,20$ and $26.29 \mathrm{dBm}$, respectively. These positions were in zones with no direct line of sight to the base station (BS) due to partial or total obstruction, links impacted by construction elements or varying degrees of wave diffraction. While mote 1 was closest to the base station, there was no line of sight between the two, and the first Fresnel zone was completely obstructed. In other words, for link 1/BS, $r_{1}=0.28 \mathrm{~m}$, for a clearance zone radius $\left(60 \%\right.$ of $r_{1}$ ) of $0.168 \mathrm{~m}$. With the corner position of the mote and the antenna attached to the adjacent wall, the clearance zone was completely obstructed, while no line of sight existed.

For links 4/BS and 5/BS, the radii of the first Fresnel zone were 0.79 and $0.95 \mathrm{~m}$, respectively (for clearance zone radii of 0.47 and $0.57 \mathrm{~m}$ ). In link 4/BS, the clearance zone between the emitter and receiver (base station) positions was completely obstructed by a wooden entrance door, while the line of sight for link 5/BS was obstructed by a stone column at the entrance to the apse, located $5 \mathrm{~m}$ from the emitter. The difference in signal loss between these two links was $2.9 \mathrm{dBm}$, which was much less than the difference between either and link 1/BS. Moreover, further to 


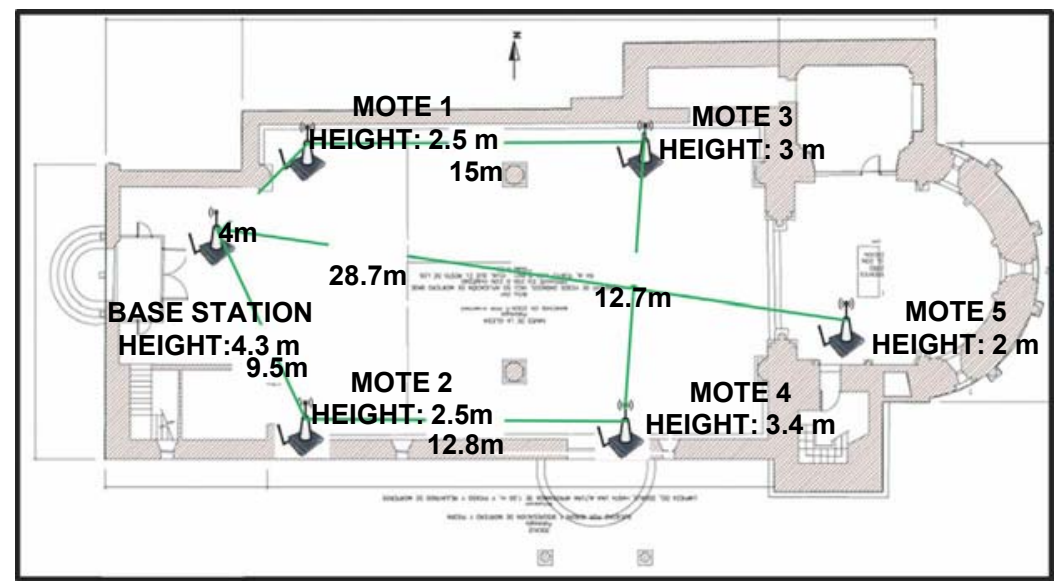

Fig. 5. Position of motes and base station in San Juan Bautista Church at Talamanca de Jarama, Madrid, Spain.

Table 2

Communications quality assessment parameters for San Juan Bautista Church at Talamanca de Jarama, Madrid, Spain.

\begin{tabular}{|c|c|c|c|c|c|c|c|c|c|}
\hline $\begin{array}{l}\text { Mote } \\
\text { ID }\end{array}$ & $\begin{array}{l}\text { Distance to base } \\
\text { station (BS) in } \\
\text { metres }\end{array}$ & $\begin{array}{l}\text { Direct line } \\
\text { of sight? } \\
\text { Yes/No }\end{array}$ & $\begin{array}{l}\text { Type of } \\
\text { obstruction }\end{array}$ & $\begin{array}{l}\text { Offset-corrected } \\
\text { RSSI (mean for } \\
\text { period, dBm) }\end{array}$ & $\begin{array}{l}\text { CORR } \\
\text { (mean for } \\
\text { period) }\end{array}$ & $\begin{array}{l}\text { Success rate (\% } \\
\text { messages } \\
\text { received) }\end{array}$ & $\begin{array}{l}\text { Repetition rate }(\% \\
\text { duplicated } \\
\text { messages) }\end{array}$ & DV $=$ Vinitial & Vfinal \\
\hline 1 & 2.5 & No & Total & 26.29 & 84.81 & 100 & 15.16 & $0.007 \mathrm{~V}$ & \\
\hline 2 & 9.5 & Yes & None & 7.47 & 107.68 & 100 & 0.07 & $0.002 \mathrm{~V}$ & \\
\hline 3 & 18.6 & Yes & None & 8.10 & 107.37 & 100 & 0.07 & $0.002 \mathrm{~V}$ & \\
\hline 4 & 20.1 & No & Total & 17.10 & 107.37 & 100 & 0.18 & $0 \mathrm{~V}$ & \\
\hline 5 & 28.7 & No & Total & 20 & 105 & 100 & 0.10 & $0.004 \mathrm{~V}$ & \\
\hline
\end{tabular}

findings for these three links with no line of sight, losses due to the presence of obstacles (total obstruction in the clearance zone near the emitter) predominated. The lowest RSSI and CORR values were observed when the obstacle was a masonry wall corner (mote 1 , Table 2 ). The RSSI values were less impacted by timber elements positioned near the antenna (mote 4, Table 2) where, despite the greater emitter-receiver distance than in mote 1 , the communications quality parameters exhibited higher values.

The position of mote 1 in a corner generated a host of reflections in the direction opposite to the path of the wave to the base station, with the concomitant percentage of signal loss. The RSSI was $6.29 \mathrm{dBm}$ lower than for link 5/BS in which the obstacle was neither a corner nor near the emitter. Consequently, the link quality indicated by the correlation value, at 84.81, was lower for 1/BS than any other link, while the CORR values for links 4/BS and 5/BS were near the 110 excellence mark. The percentage of duplicated messages received from mote 1 was likewise significant (Table 2). In links with a line of sight, the distance between the mote and the base station had virtually no impact on the RSSI and CORR values. The findings for motes 3 and 2 were cases in point, for despite the 9.1-m difference in the distance to the receiver, the values of these parameters barely varied.

While the mote farthest from the base station (mote 5) and the mote in a corner position (mote 1) with a large number of reflections interfering with the wave, exhibited the highest power demand, the absolute rise over the initial voltage was close to nil in both cases.

\subsubsection{Santo Domingo de Silos, Pinto, Madrid, Spain}

The same network design was deployed in Santo Domingo de Silos Church at Pinto, Madrid, Spain (40 $14^{0} 28^{01} \mathrm{~N}$, $341^{0} 58^{01} \mathrm{~W}$ ) to assess communications quality in a building of similar construction but larger dimensions. This fourteenth-century Romanesque church with Gothic rooftops, measuring $41.25 \quad 20.78 \quad 15.65 \mathrm{~m}$, underwent major reform in the fifteenth and sixteenth centuries. The main façade and bell tower were rebuilt with brick and limestone rubble in the mid-twentieth century. The communications quality study, conducted with a 5-mote design analogous (Fig. 6) to the one used in San Juan Bautista Church at Talamanca de Jarama, was conducted between 4 and 23 December 2013 for a total of 19 full days. The sampling period was every $5 \mathrm{~min}$ in all except one mote, mote 2, where 1-min sampling was conducted to study the effect of this rise in the data acquisition rate on the RSSI and CORR values.

When the study of parameters RSSI and CORR was based on the distance to the base station (Table 3), two distinct areas were observed: the RSSI was higher for the motes close to the receiver (motes 1 and 2) and lower in the intermediate zones (motes 3 and 4) and in the node farthest away, in the apse (mote 5), for which the lowest CORR value was also recorded.

The link quality denoted by the correlation (CORR) value was practically the same for links 1/BS and 2/BS, whereas the difference in their received signal strength indicators (RSSI), a measure of the degree of partial obstruction in the first Fresnel clearance zone, was 


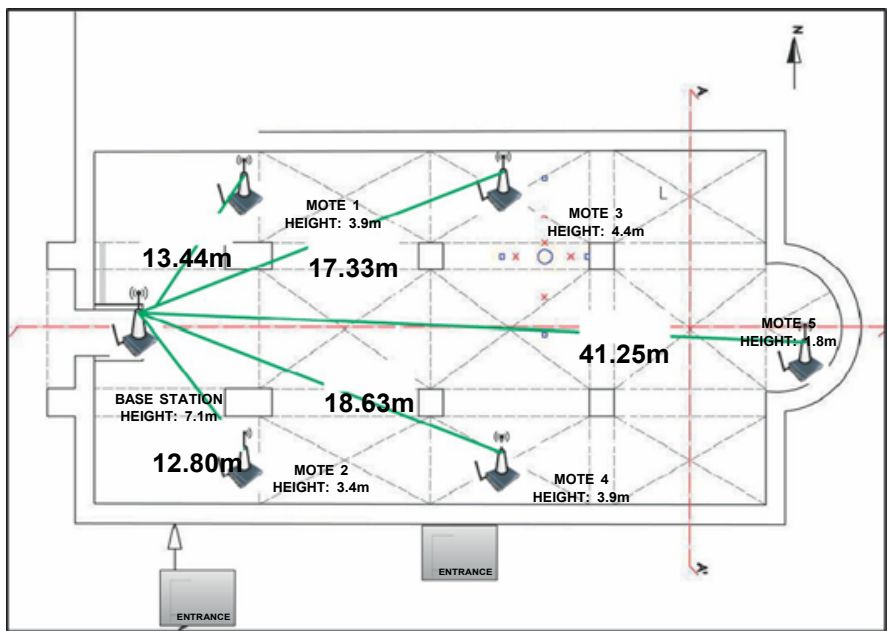

Fig. 6. Mote distribution in Santo Domingo de Silos Church at Pinto, Madrid, Spain.

Table 3

Range, power demand and communications quality findings for sensors in Santo Domingo de Silos Church at Pinto, Madrid, Spain.

\begin{tabular}{llllllll}
\hline $\begin{array}{l}\text { Mote } \\
\text { ID }\end{array}$ & $\begin{array}{l}\text { Distance to base } \\
\text { station (BS) in } \\
\text { metres }\end{array}$ & $\begin{array}{l}\text { Direct line of } \\
\text { sight? Yes/No }\end{array}$ & $\begin{array}{l}\text { Type of } \\
\text { obstruction }\end{array}$ & $\begin{array}{l}\text { Offset-corrected } \\
\text { RSSI (mean for } \\
\text { period, dBm) }\end{array}$ & $\begin{array}{l}\text { CORR (mean } \\
\text { for period) }\end{array}$ & $\begin{array}{l}\text { Success rate } \\
\text { (\% messages } \\
\text { received) }\end{array}$ & $\begin{array}{l}\text { Repetition } \\
\text { rate(\% of } \\
\text { duplicated } \\
\text { messages) }\end{array}$ \\
\hline 1 & 13.44 & Yes & Partial & 6.31 & 107.69 & 100 & 0.42 \\
2 & 12.80 & Yes & Partial & 16.16 & 107.85 & 100 & 0.46 \\
3 & 17.33 & No & Total & 27.43 & 88 & 86.42 & 0 \\
4 & 18.63 & Yes & Partial & 22.97 & 105.74 & 100 & 0.4 \\
5 & 41.25 & Yes & None & 22.46 & 77.20 & 100 & $0.016 \mathrm{~V}$ \\
13.2 & $0.007 \mathrm{~V}$ \\
\hline
\end{tabular}

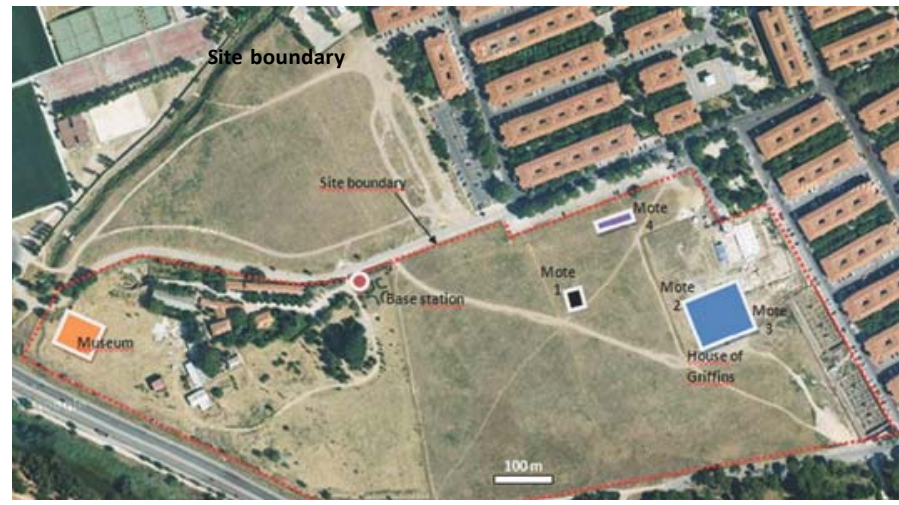

Fig. 7. Mote positions at the Complutum archaeological site, Alcalá de Henares, Madrid, Spain.

$9.85 \mathrm{dBm}$. Although obstruction, like the data acquisition rate, was greater in 2 than 1, no material changes were recorded in battery consumption. Nonetheless, in light of the findings, the higher acquisition rate was deemed advisable for subsequent installations involving longer ranges. In all cases, the obstacles in this church were the triptychs, made primarily of cedar wood. Exceptionally, mote 3 was partially obstructed by wooden and metal ornaments at the top of the triptych near the antenna. As a result of that obstacle and a stone column positioned just $5 \mathrm{~m}$ from the antenna in the line of sight between it and the receiver, the link had no line of sight (NLoS, $60 \%$ of $r_{1}=0.74 \mathrm{~m}$ ), as shown in Fig. 7. In other words, the lower RSSI ( $27.43 \mathrm{dBm})$ and CORR (88) values were due to the interference of construction elements as well as metals that caused absorption-induced strength losses in the signal transmitted [32], leading to a loss in the number of messages received. In link 5/BS, despite the considerable difference in the distance to the base station, the RSSI value was excellent thanks to the existence of a line of sight (LoS). 
Nonetheless, the value was smaller than recorded for the motes with LoS in San Juan Bautista Church at Talamanca de Jarama, Madrid, Spain, for here the distance was twice as large. The CORR value, as expected, declined in proportion to the link quality.

In this installation the power demand values were observed to be similar for success rates of $100 \%$, while battery consumption was not significantly impacted by the data acquisition rate.

\subsection{Archaeological heritage and museum assets}

Network monitoring and testing were conducted at the Complutum archaeological site, a compound with archaeological remains named after an ancient Roman city located where the town of Alcalá de Henares stands today, on the outskirts of Madrid, Spain (40 $28^{0} 00^{n} \mathrm{~N}, 322^{0} 00^{10} \mathrm{~W}$ ). The Roman city was built in the first century of the Christian era and rehabilitated and reformed in the third. The enclave was close to several major imperial roads as well as to the River Henares and its fertile valley. The Romans remained in the area for around six hundred years, from the first century through the fall of the empire.

Two of the monitoring points were positioned on the House of Griffins (motes 2 and 3, Fig. 7) [15], one of the compound's largest (around $1000 \mathrm{~m}^{2}$, including house and courtyard) and most comfortable homes and the site's central element. It was in use until the fourth century when it was destroyed by fire. A third was placed on the information booth alongside the entrance (mote 1, Fig. 7) and a fourth in an area with replicas of Roman building foundations (mote 4, Fig. 7) [15].

Complutum was listed as a cultural heritage asset (Spanish initials, BIC) in 1988 and since 2008 forms part of the network of outdoor archaeological museums open to the public in the region of Madrid, Spain. The measurement campaign at the archaeological site and museum was conducted for 14 full days, from 29 January to 11 February 2014, with a 1-min data acquisition rate at all motes to verify their power demand at longer distances than in the previous campaigns. In addition, this installation (Fig. 7) was designed to analyse the effect of adverse weather (wind gusts of up to $2.14 \mathrm{~m} / \mathrm{s}$, below freezing temperatures and relative humidity values of $100 \%$ ) on the communications parameters assessed (Table 4).
Motes were also positioned inside the museum associated with the site to analyse the effect of indoor differences in elevation (motes 5 and 6) on communications quality, as in this case the base station was located in the first basement of the museum. The shop and materials storage rooms monitored were also located below grade (basements 1 and 2, respectively).

The data success rate for the archaeological site (motes 1-4) was 100\% except for mote 2. In addition to being one of the nodes farthest from the base station, it was positioned in a corner where the presence of steel fences completely obstructed the Fresnel clearance zone; this was the factor that impacted the RSSI and CORR values most adversely. Moreover, given its below grade location, it had no line of sight with the base station. The RSSI value for this link was observed to be very similar to the value recorded for mote 1 in San Juan Bautista Church at Talamanca de Jarama (Fig. 5), where the mote-base station distance was $312.5 \mathrm{~m}$ shorter. The conclusion drawn, then, was that a corner location in which the antenna was obstructed by construction elements in the Fresnel clearance zone played a prominent role in the low RSSI value (compared to unobstructed line of sight conditions), whereas the distance to the base station was scantly significant in this regard. Nonetheless, distance was found to have an impact on the percentage of duplicated messages, which was significant at short (mote 1, Table 2) and nil for long (mote 2, Table 4) distances. The correlation value, in turn, which is indicative of the quality of the frame received and proportional to link quality, was affected by the characteristics of the obstacle, declining by nearly $20 \%$ in the presence of plastered brick walls and by $40 \%$ (to a value close to 50 , the minimum quality perceivable by the radio transceiver used) where the obstacles were metallic. In the latter case a $36.7 \%$ loss of received messages was recorded: i.e., the CORR value was observed to be closely related to the percentage of data successfully received. This campaign showed that when the obstruction consisted of metallic objects, message loss was greater in the presence of total obstruction of the Fresnel clearance zone due to a corner location and less notorious otherwise (Table 3, mote 3, where the correlation value was 88 and message loss stood at $13.58 \%$ )

In link 6/BS, inside the archaeological museum, the base station was located in a corridor and the mote in an adjacent room (the straight line distance between the two

Table 4

Findings for communications network at Complutum archaeological site and museum.

\begin{tabular}{|c|c|c|c|c|c|c|c|c|c|}
\hline Mote ID & $\begin{array}{l}\text { Distance to base } \\
\text { station (BS) in } \\
\text { metres }\end{array}$ & $\begin{array}{l}\text { Direct line } \\
\text { of sight? } \\
\text { Yes/No }\end{array}$ & $\begin{array}{l}\text { Type of } \\
\text { obstruction }\end{array}$ & $\begin{array}{l}\text { Offset-corrected } \\
\text { RSSI (mean for } \\
\text { period, dBm) }\end{array}$ & $\begin{array}{l}\text { CORR } \\
\text { (mean for } \\
\text { period) }\end{array}$ & $\begin{array}{l}\text { Success rate }(\% \\
\text { messages } \\
\text { received) }\end{array}$ & $\begin{array}{l}\text { Repetition rate (\% } \\
\text { of duplicated } \\
\text { messages) }\end{array}$ & DV = Vinitial & Vfinal \\
\hline \multicolumn{10}{|c|}{ Archaeological site } \\
\hline 1 & 180 & No & Total & 15 & 107.5 & 100 & 0.10 & $0.012 \mathrm{~V}$ & \\
\hline 2 & 315 & No & Total & 26 & 60.1 & 66.3 & 0 & $0.004 \mathrm{~V}$ & \\
\hline 3 & 345 & No & Total & 12.92 & 106 & 100 & 0.09 & $0.006 \mathrm{~V}$ & \\
\hline 4 & 289 & No & Total & 11.16 & 107.31 & 100 & 0.08 & $0.031 \mathrm{~V}$ & \\
\hline \multicolumn{10}{|c|}{ Museum } \\
\hline 5 & Storey-2 & No & Total & 26.12 & 97.5 & 100 & 0 & $0.009 \mathrm{~V}$ & \\
\hline 6 & Storey-1 & No & Total & 21.96 & 100.89 & 100 & 0.10 & $0.017 \mathrm{~V}$ & \\
\hline
\end{tabular}


was approximately $10 \mathrm{~m}$ ) behind a closed door and walls. Mote 5, in contrast, was positioned on a lower storey (with a concrete floor slab in between), which affected the RSSI and CORR values. Inasmuch as the values for the data acquired were similar to the information recorded for same-level monitoring (motes 3, 4 and 5, Table 3) when the straight line distances to the base station were over $15 \mathrm{~m}$, the fact that base station and mote were on different storeys could be said to have no material effect on monitoring accuracy.

The indoor mote positioned on a different storey than the base station exhibited nearly double the energy demand as the mote located on the same storey. Of the outdoor sensors, the highest demand was observed for motes 1 and 4, where although the distances were smaller, more obstacles obstructed the wave path (information booth in mote 1 and timber beam roof in mote 4). These obstacles nonetheless had a lesser impact on communications quality due to the absence of metallic elements in the vicinity of the antenna.

\subsection{Natural heritage}

\subsubsection{Risco de las Cuevas}

Risco de las Cuevas is a gypsum escarpment where caves were excavated in the solid rock between the late Neolithic and much more recent times (Fig. 8). It is located at Perales de Tajuña, Madrid, Spain $\left(40 \quad 14^{0} 0.83^{10} \mathrm{~N}, 319^{0} 55\right.$. $\left.85^{\infty} \mathrm{W}\right)$, where it rises to a height of $70 \mathrm{~m}$ and runs SW-NE for a total of $500 \mathrm{~m}$. The carved dwellings were listed as a historic-artistic monument in 1931 and as a cultural heritage asset in 1988. The weathering to which the formation is exposed may compromise its integrity [14]: thermal expansion may induce crystal loss or fracture which, in conjunction with area tectonics, may accelerate or contribute to large-scale spalling.

The area was monitored between 17 February and 4 March 2014 (16 days). Data were acquired minute-byminute to observe the effect of terrain characteristics on the parameters assessed under exhaustive monitoring conditions.

Table 5 below gives the findings on communications quality.

In the Risco de las Cuevas campaign at Perales de Tajuña, the effect of the in-cave reflections on communications quality was established as an additional assessment parameter (except for mote 2, which was positioned in a crack with no line of sight to the base station). In these cases, although the long distance between the mote and the base station was completely clear, the first part of the path was highly impacted by reflections inside the caves (with gypsum as the obstructive material). Moreover, the location of the base station on a road adjacent to the caves was at a 45-50 angle with respect to the motes, given the grade on the terrain (Fig. 9). The correlation value for caves 3 and 4 was slightly lower than for the other two due to cave morphology (mote 3 and its antenna were positioned more inwardly in the cave) and the greater distance to the base station. While energy demand was not significant, it was higher here than in the preceding two installations, a finding attributed to the prior use of the batteries and the conditions described.
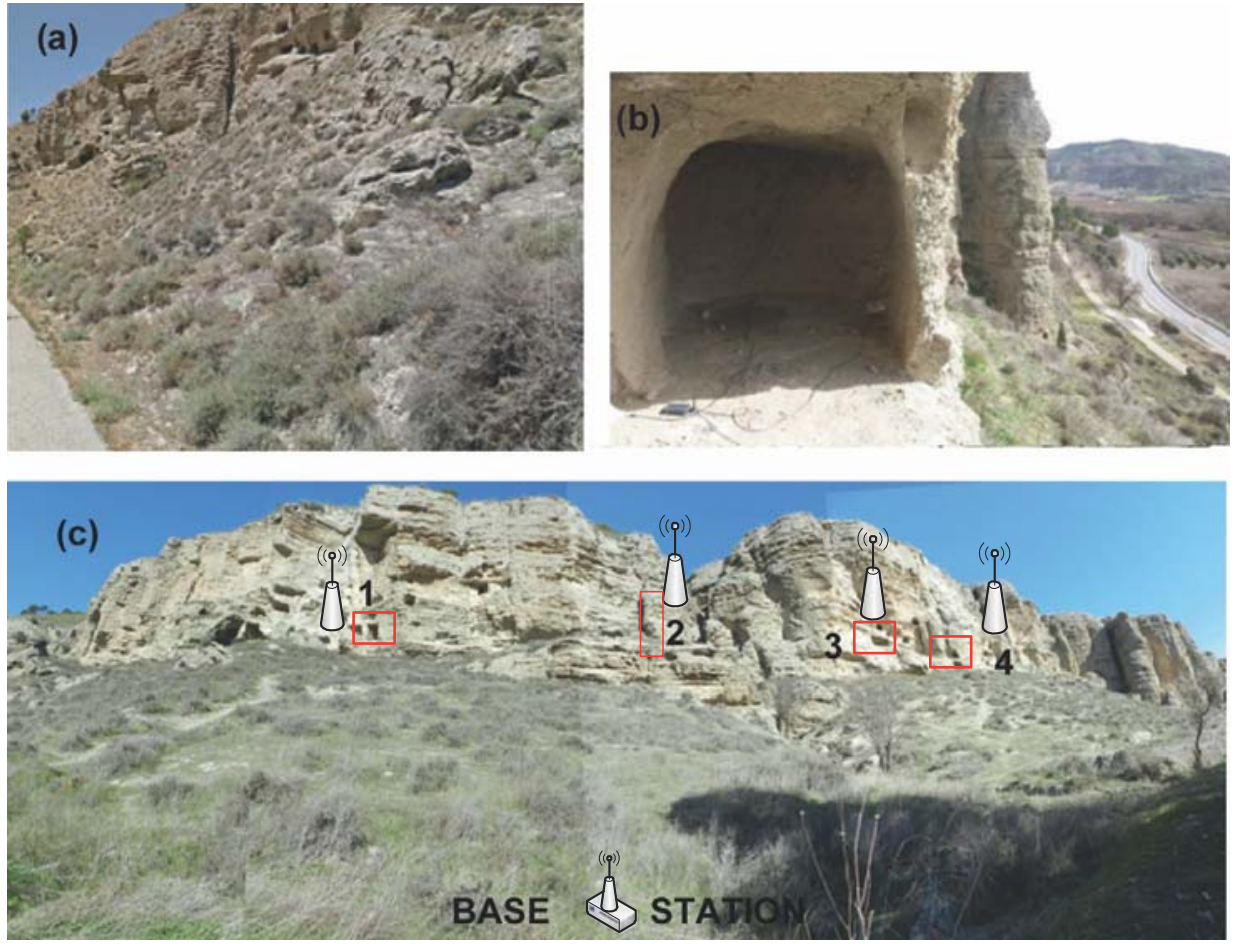

Fig. 8. Network installation at Risco de las Cuevas, Perales de Tajuña, Madrid, Spain: (a) grade on terrain between the base station and caves; (b) sensor installation in mote 3 cave; (c) overview of Risco de las Cuevas showing the positions of the wireless sensor network measuring points. 
Table 5

Communications assessment values at Risco de las Cuevas, Perales de Tajuña, Madrid, Spain.

\begin{tabular}{llllllll}
\hline $\begin{array}{l}\text { Mote } \\
\text { ID }\end{array}$ & $\begin{array}{l}\text { Distance to } \\
\text { base station } \\
\text { (BS) in metres }\end{array}$ & $\begin{array}{l}\text { Direct line of } \\
\text { sight? Yes/No }\end{array}$ & $\begin{array}{l}\text { Type of } \\
\text { obstruction }\end{array}$ & $\begin{array}{l}\text { Offset-corrected } \\
\text { RSSI (mean for } \\
\text { period, dBm) }\end{array}$ & $\begin{array}{l}\text { CORR (mean } \\
\text { for period) }\end{array}$ & $\begin{array}{l}\text { Success } \\
\text { rate (\% } \\
\text { messages } \\
\text { received) }\end{array}$ & $\begin{array}{l}\text { Repetition } \\
\text { rate }(\% \text { of } \\
\text { duplicated } \\
\text { messages) }\end{array}$ \\
\hline 1 & 71.75 & No & Total & 14.7825 & 100.6 & 72.4 & 0 \\
2 & 49.36 & No & Total & 16.425 & 107.43 & 100 & 0 \\
3 & 70 & No & Total & 19.125 & 95.5 & 100 & 0.92 \\
4 & 79.40 & No & Total & 23.945 & 97.5 & 100 & $0.057 \mathrm{~V}$ \\
\hline
\end{tabular}

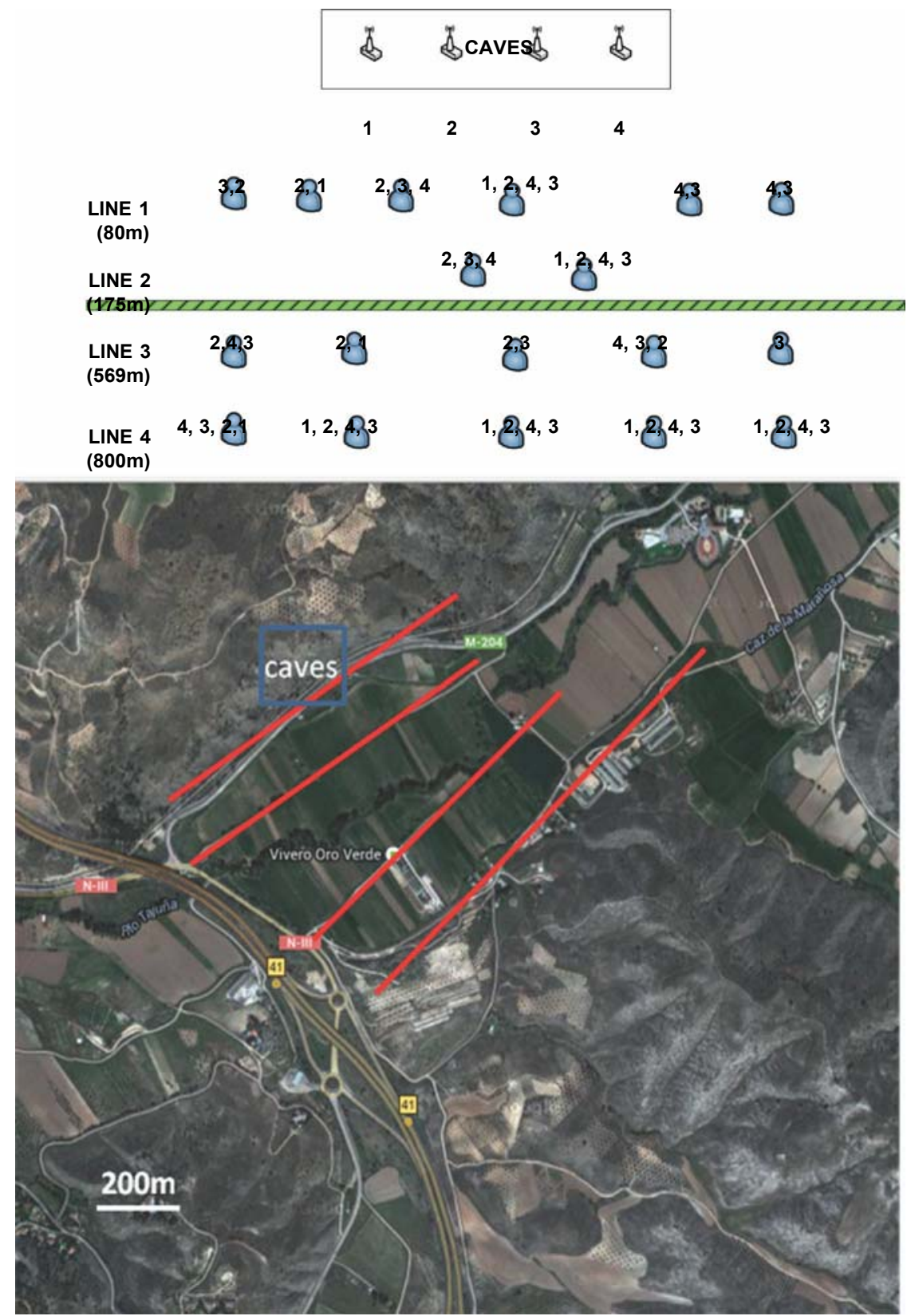

Fig. 9. Range tests for the installation at Risco de las Cuevas, Perales de Tajuña, Madrid, Spain: aerial photograph of the zone, showing range test lines (in red). (For interpretation of the references to color in this figure legend, the reader is referred to the web version of this article.) 
Despite the difficulties posed by the enclave, in three of the four caves monitored, $100 \%$ of the data were received. The exception was mote 1 , where $20 \%$ of the information was lost, even though the RSSI and CORR parameters were indicative of stable communications. In this case, in addition to the 50 grade to the base station, the inside of the cave was likewise sloped. As a result, the mote had to be scotched with a piece of gypsum from the cave itself to prevent it from sliding out of position. The position of the scotch close to the antenna and cave characteristics were therefore the factors that induced the decline in the percentage of data received. A small percentage of duplicated messages, albeit larger than for the remaining caves, was received for caves 3 and 4 (Fig. 8).

The highest energy demand was observed for motes 2 and 3 , the former characterised by the lack of a line of sight to the base, due to its position in a crack and the presence of a rise in the terrain that blocked the path entirely; and the latter, which also exhibited the lowest CORR value, by a particularly high intensity of reflections.

A series of tests were run at distances of nearly $1 \mathrm{~km}$ as shown in Fig. 9 to check network performance in an open area flanked with trees (Fig. 9, rectangle between lines 2 and 3) and similar elements in such enclaves.

The mote positions were not varied, while the base station was shifted for $5 \mathrm{~min}$ to check reception. The mote numbers in green in the figure mean satisfactory reception, blue intermittent reception and red no reception from the mote at the point in question.

The distances shown in Fig. 9, measured with Google Earth, were taken from the midpoint between caves 2 and 3 to the midpoint between the lines assessed. The assessment points for a given line were spaced at approximately $150 \mathrm{~m}$.

\subsubsection{The Jameos del Agua Lava Tube (Lanzarote, Canary} Islands)

Jameos del Agua, like Cueva de los Verdes, is located inside the lava tube generated when a volcano known as Corona erupted on Lanzarote, Canary Islands, Spain $\left(299^{0} 27^{10} \mathrm{~N}, 1325^{0} 52^{\infty} \mathrm{W}\right.$ ). Jameos del Agua is sited in the section of tube closest to the coast. The name ("agua" means water in Spanish) refers to the existence of a lake inside the tube, a geologically singular formation. Thanks to that singularity, the area has merited two types of environmental protection. On the one hand, it is located within the Malpaís de la Corona Natural Monument, and on the other, it is listed as a scientific and cultural asset, the latter with historic garden status (1998).

The monitoring period was divided into two stages for reasons of institutional organisation: from 19 May to 14 June (27 days) and 24 to 30 June (7 days). The values shown below are the means for the two periods.

The mote positions are labelled as S1, S2, S3 and S4 (Fig. 10). Communications quality was assessed for the last three. $\mathrm{R}$ indicates the position of the base station.

Motes 2, 3 and 4 were located in areas with pedestrian traffic, for visitors cross a footbridge that runs from mote 4 to mote 2. Mote 3 stood opposite the base station (R). The lake was the closest element affecting communications. The location of the base station, near a volcanic boulder, impacted reception, especially from S4 [33].

Mote S4 was fitted with a 2-m SMA antenna extension (S4, Table 6) to test losses attributable to such set-ups.

The findings are given in Table 6.
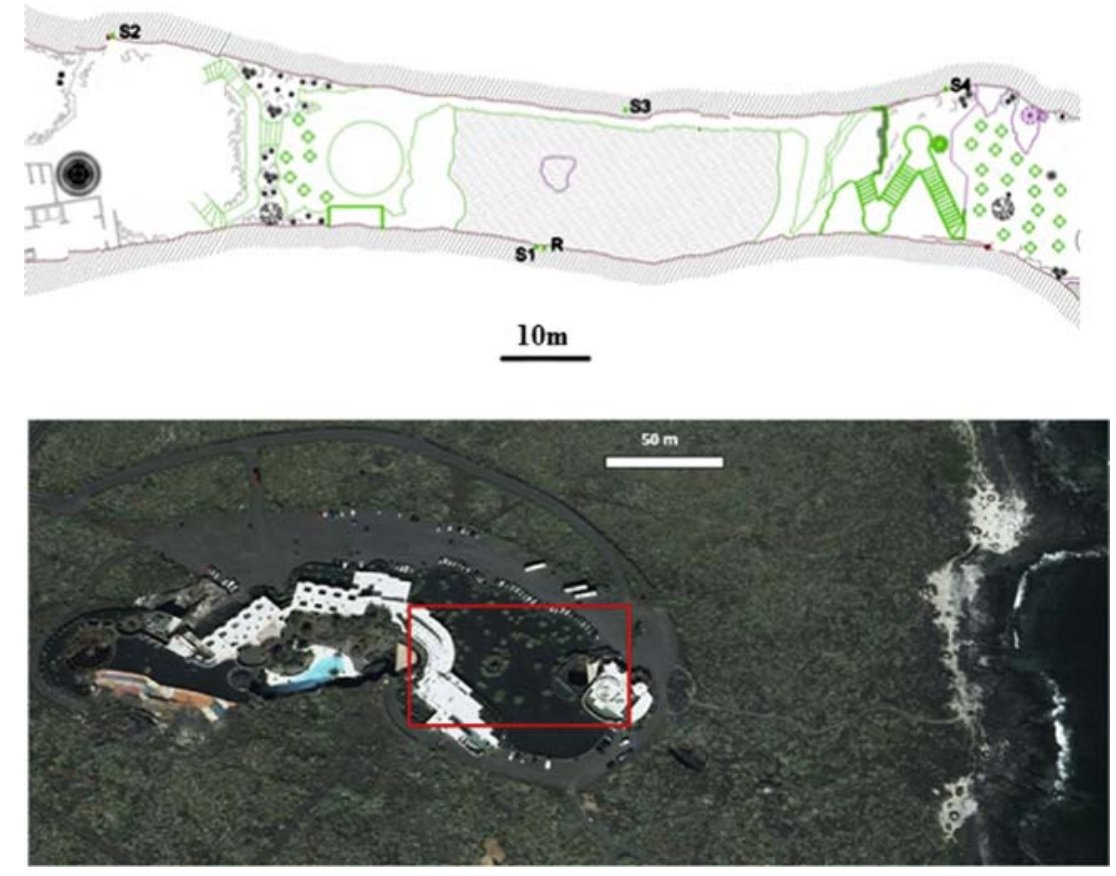

Fig. 10. Position of monitoring points for link quality testing at Jameos del Agua, Lanzarote, Spain: Aerial photograph of the zone, showing an selected area (red rectangle). (For interpretation of the references to color in this figure legend, the reader is referred to the web version of this article.) 
Table 6

Communications assessment parameters for Jameos del Agua, Lanzarote, Canary Islands, Spain.

\begin{tabular}{llllllll}
\hline $\begin{array}{l}\text { Mote } \\
\text { ID }\end{array}$ & $\begin{array}{l}\text { Distance to base } \\
\text { station (BS) in } \\
\text { metres }\end{array}$ & $\begin{array}{l}\text { Direct line of } \\
\text { sight? Yes/No }\end{array}$ & $\begin{array}{l}\text { Type of } \\
\text { obstruction }\end{array}$ & $\begin{array}{l}\text { Offset-corrected } \\
\text { RSSI (mean for } \\
\text { period, dBm) }\end{array}$ & $\begin{array}{l}\text { CORR (mean } \\
\text { for period) }\end{array}$ & $\begin{array}{l}\text { Success rate } \\
\text { (\% messages } \\
\text { received) }\end{array}$ & $\begin{array}{l}\text { Repetition rate } \\
\text { (\% of duplicated } \\
\text { messages) }\end{array}$ \\
\hline S2 & 56.67 & No & Total & 17.95 & 105.55 & 100 & 0.089 \\
S3 & 18.33 & No & Total & 8.16 & 104.8 & 100 & 0.098 \\
S4 & 50 & No & Total & 23.10 & 104.53 & 97.63 & 0 \\
\hline
\end{tabular}

Table 7

Estimated costs of wireless sensor network monitoring for 5 years in the scenarios described.

\begin{tabular}{|c|c|c|c|c|c|}
\hline Monitoring campaign & $\begin{array}{l}\text { Number of } \\
\text { devices per } \\
\text { scenario }\end{array}$ & $\begin{array}{l}\text { Number of } / \mathrm{TH} \\
\text { sensors per scenario }\end{array}$ & $\begin{array}{l}\text { First-year } \\
\text { monitoring costs } \\
\text { (Euro) }\end{array}$ & $\begin{array}{l}\text { Cost of replacing mote } \\
\text { batteries (Euro) }\end{array}$ & $\begin{array}{l}\text { Cost of monitoring } \\
\text { campaign over } \\
5 \text { years (Euro) }\end{array}$ \\
\hline $\begin{array}{l}\text { San Juan Bautista Church at } \\
\text { Talamanca de Jarama, Madrid, } \\
\text { Spain }\end{array}$ & $\begin{array}{l}5 \text { motes } \\
\text { 1base station }\end{array}$ & 20 & 4565 & 300 & 4865 \\
\hline $\begin{array}{l}\text { Santo Domingo de Silos, Pinto, } \\
\text { Madrid, Spain }\end{array}$ & $\begin{array}{l}5 \text { motes } \\
1 \text { base station }\end{array}$ & 20 & 4565 & 300 & 4865 \\
\hline $\begin{array}{l}\text { Complutum archaeological site, } \\
\text { Alcalá de Henares, Madrid, Spain }\end{array}$ & $\begin{array}{l}4 \text { motes } \\
1 \text { base station }\end{array}$ & 16 & 3765 & 240 & 4005 \\
\hline $\begin{array}{l}\text { Complutum museum, Alcalá de } \\
\text { Henares, Madrid, Spain }\end{array}$ & $\begin{array}{l}2 \text { motes } \\
1 \text { base station }\end{array}$ & 8 & 2165 & 120 & 2285 \\
\hline $\begin{array}{l}\text { Risco de las Cuevas, Perales de Tajuña, } \\
\text { Madrid, Spain }\end{array}$ & $\begin{array}{l}4 \text { motes } \\
1 \text { base station }\end{array}$ & 16 & 3765 & 240 & 4005 \\
\hline $\begin{array}{l}\text { Jameos del Agua Lava Tube Lanzarote, } \\
\text { Canary Islands, Spain }\end{array}$ & $\begin{array}{l}4 \text { motes } \\
1 \text { base station }\end{array}$ & 16 & 3765 & 240 & 4005 \\
\hline
\end{tabular}

As at Risco de las Cuevas, the RSSI values recorded were very close to or higher than $20 \mathrm{dBm}$ in most cases. The lowest RSSI observed was for S4, even though it and S2 were at a similar distance from the base station. While this mote, fitted with the antenna extension, exhibited a slightly lower RSSI than the others, it was operational, for its success rate was only barely under the $100 \%$ recorded for the other links. It also had the network's lowest CORR value. The duplicated message rate was slightly lower in the lava tube than at Risco de las Cuevas, while the mote-base station distance was also shorter and the terrain between the base station and the motes was not sloped as in the cave installation. The RSSI for mote 3 was over $9 \mathrm{dBm}$ higher than the values for S2 and S4, an indication that despite the very good quality of the communications established (RSSI > $40 \mathrm{dBm}$, CORR nearly 110), in such installations the emitter - receiver distance affected the received signal strength indicator.

In this campaign S3 and S4 exhibited the highest battery consumption, which was practically negligible in S2. While the distance between S3 and the base station was shorter than in the other two cases, the area was affected by heavier pedestrian traffic, while the set-up at S4 included an antenna extension and greater obstruction. Battery consumption was higher at Jameos del Agua than in the other four scenarios studied.

\section{Discussion}

In the indoor heritage environments studied (churches and museum), the RSSI and CORR values declined drastically when the emitting mote was positioned in a corner that obstructed $60 \%$ of the radius in the Fresnel clearance zone. That decline in communications quality did not affect the percentage of successfully received messages when the emitter-receiver distance was small (mote 1, Table 2), although the percentage of duplicated messages did rise. When the emitter-receiver distance was over $15 \mathrm{~m}$, however, and the clearance zone was obstructed by the presence of construction elements in the line of sight to the base, the successful message rate declined (mote 3, Table 3).

Where no corners were involved and the distance to the base station was around $15 \mathrm{~m}$ or slightly over in motes with an unobstructed or partially obstructed line of sight, the RSSI values were greater than $20 \mathrm{dBm}$. At distances of or close to $20 \mathrm{~m}$ the RSSIs were lower than $20 \mathrm{dBm}$. The presence of metallic elements and other obstacles in the path followed by the wave to the base station had a more adverse impact on the RSSI than the distance between emitter and receiver. With an unobstructed line of sight, indoor distances of up to $40 \mathrm{~m}$ had a practically imperceptible effect on the received signal strength, even though the correlation value declined visibly (mote 5, Table 3), lowering the success rate. When in addition to the presence of interference, mote and base station were on different storeys, as in the Complutum Museum, the RSSI dropped to $23 \mathrm{dBm}$.

The CORR values recorded were near 110 in most cases, and declined only where the motes were positioned in corners, construction elements wholly or partially obstructed the first Fresnel radius clearance zone $\left(60 \%\right.$ of $\left.r_{1}\right)$ or the link range was over $40 \mathrm{~m}$, even in the presence of a line of sight between mote and base station. 
In the outdoor heritage scenarios studied (archaeological sites, caves, lava tubes), much longer distances (up to a maximum of $345 \mathrm{~m}$ recorded at the Complutum archaeological site) could be obtained without altering the RSSI values, which ranged from 10 to $15 \mathrm{dBm}$ in motes 1,3 and 4 (Table 4). In the House of Griffins, where the distances were similar (315 m for mote 2 and $245 \mathrm{~m}$ for mote 3: Table 4), the RSSI value declined to $25 \mathrm{dBm}$ and the correlation to 60.1 in the first of the three. Here the combination of two factors jeopardised communications quality: the location of mote 2 in a corner and the nature of the obstacle, which rather than a masonry wall was a steel fence. These two impediments to communications quality, added to the considerably longer distance to the base sta- tion than the few dozen metres tested in indoor environments, induced a visible decline in the RSSI and CORR values. These parameters exhibited a similar range for inter-storey and intra-storey monitoring when the distance involved was over $15 \mathrm{~m}$ and the emitter-receiver line of sight was obstructed. For distances of over $40 \mathrm{~m}$, while signal strength was unaffected, link quality was lower.

In the outdoor scenarios, the RSSI values were greater than the $40 \mathrm{dBm}$ excellence standard [29] in all cases, despite the huge distances between the motes and base station, while human traffic had no material effect on communications quality inside the lava tube. When the terrain between the base station and the emitter mote was not sloped, despite the long distances covered, the RSSIs

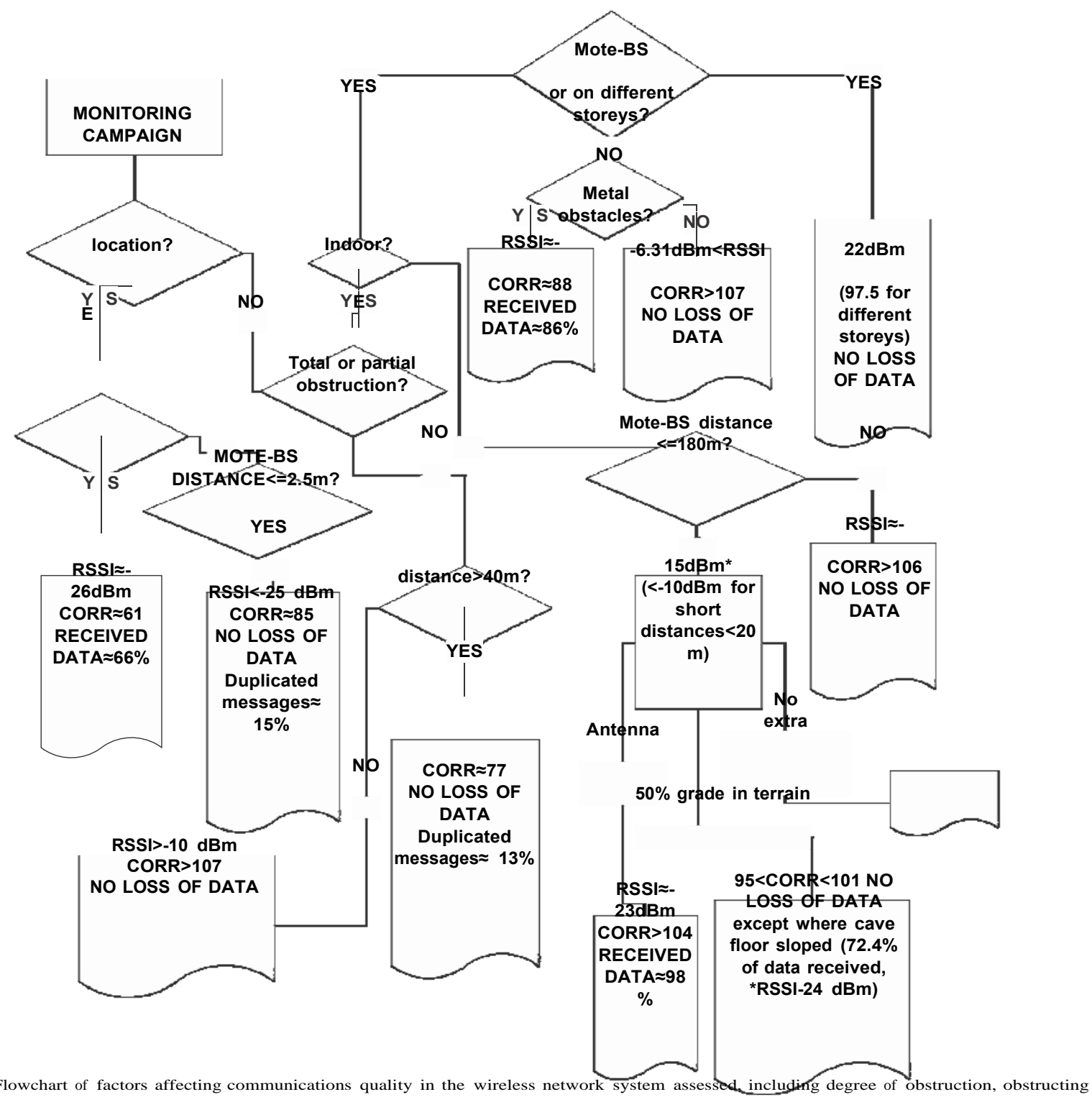

Fig. 11. Flowchart of factors affecting communications quality in the wireless network system assessed, including degree of obstruction, obstructing materials and mote-base station distances, as well as RSSI and CORR results and success rates. 
ranged from 10 to $15 \mathrm{dBm}$. The CORRs, in turn, were close to the 110 received frame excellence value except where the motes were positioned in corners and near metal, when they declined drastically. The existence of slopes or grades in the terrain between motes and base station, even at much shorter distances $(70-80 \mathrm{~m}$, see Table 5$)$, shifted the RSSIs to the 15 to $25 \mathrm{dBm}$ range. The CORR values, while over 95 in all cases, showed data loss where the cave floor was also sloped and the zone adjacent to the antenna was obstructed (mote 1, Table 5). At shorter outdoor distances (Table 6), the correlation values were over 104 in all cases and nearly the 110 indicative of high quality frames [30]. The RSSI values ranged from 8 to $18 \mathrm{dBm}$, except where an antenna extension was used, which induced a decline in RSSI of around $5 \mathrm{dBm}$.

In another vein, Table 7 lists the equipment maintenance costs involved in this type of installations, excluding items such as staff travel to replace depleted batteries, for instance. The market prices (including VAT) in the first half of 2015 were as follows: 565 euros for the base station, 95 for the T/RH sensor with sintered polyethylene protection as described in 2.1, 420 for each sensor with four digital input/output ports (including the $3.6-\mathrm{V}$ battery) and 30 for the $3.6-\mathrm{V}$ lithium batteries that power the motes.

The price range and minimal maintenance costs of this type of installations explain the utility and widespread adoption of wireless sensor network monitoring in many new fields, including heritage conservation.

\section{Conclusions}

The factors that attenuate communications quality and the degree of attenuation can be deduced from the foregoing. A distinction can likewise be drawn between indoor and outdoor environments, including conditioning factors such as terrain characteristics. The resulting scheme is set out in Fig. 11.

The general conclusion is that the findings for the network assessed were excellent in most cases, both in terms of quality, with RSSIs of $>40 \mathrm{dBm}$ and CORR values of around 110, and of the percentage of data successfully received, normally $100 \%$. The network was assessed under different conditions to establish a general method applicable to any manner of wireless network installed in heritage environments, a question not addressed in the literature to date. The most detrimental factor was found to be total obstruction of the emitting antennas by adjacent metallic materials (Fig. 11), followed by partial/total obstruction at medium or long range distances depending on the material involved. The use of antenna extensions and the presence of significant numbers of harmful reflections have a direct and adverse impact on RSSI values in specific cases, such as the existence of sloping terrain in and around caves. Similar conditions may be found in large cathedrals where motes need to be installed in domes and the base station at the entrance to the temple.

The network assessed exhibited a very low energy demand even in long range communications in indoor and outdoor scenarios, and delivered high performance when exposed to very adverse weather conditions. The variations in battery consumption were insignificant in all cases, guaranteeing the reliability of long-term monitoring with the system assessed. In the mote exhibiting the highest consumption in all the scenarios studied, the decline in the original battery charge after continuous data logging was just $1.43 \%$.

This type of multi-sensor networks will be instrumental for assessing the many parameters that need to be monitored in the preventive conservation of the cultural heritage, including visitor traffic flows, seasonal thermal lags or variations in humidity and the concentration of pollutant gases in heating system assessments.

\section{Acknowledgments}

The cooperation received from the Laboratory Network in Science and Technology for Heritage Conservation (RedLabPat, CEI Moncloa), the Diocese of Alcalá and Father Alfonso, Pinto church pastor, is gratefully acknowledged. The present study was funded under projects CGL201127902, GEOMATERIALES 2 (S2013/MIT-2914). M.I. Martí nez-Garrido's participation was supported by a Moncloa Campus of International Excellence (UCM-UPM) PICATA pre-doctoral fellowship. The manuscript was edited by Margaret Clark, professional translator and English language science editor.

\section{References}

1] F. Leccese, Remote-control system of high efficiency and intelligen street lighting using a zigbee network of devices and sensors, IEEE Trans. Power Delivery 28 (2013) 21-28.

[2] F. Mieyeville, M. Ichchou, G. Scorletti, D. Navarr, W. Du, Wireless sensor networks for active vibration control in automobile structures, Smart Mater. Struct. 21 (7) (2012) (Paper number: 075009).

[3] O. Casas, M. López, M. Quílez, X. Martínez-Farre, G. Hornero, C. Rovira, M.R. Pinilla, P.M. Ramos, B. Borges, H. Marques, P. Silva Girão, Wireless sensor network for smart composting monitoring and control, Measurement 47 (2014) 483-495.

[4] P. Daponte, L. De Cito, F. Picariello, S. Rapuano, I. Tudosa, Prototype design and experimental evaluation of wirelesss measurement nodes for road safety, Measurement 57 (2014) 1-14.

[5] M. Benedetti, L. Ioriatti, M. Martinelli, F. Viani, Wireless sensor network: a pervasive technology for earth observation, IEEE $J$. Selected Topics Appl. Earth Observ. Remote Sens. 3 (4) (2010) 431444.

[6] B. Fong, N. Ansari, A.C.M. Fong, Prognostics and health management for wireless telemedicine networks, IEEE Wirel. Commun. 19 (2012) 83-89.

[7] R. Paoli, F.J. Fernández-Luque, G. Doménech, F. Martínez, A system for ubiquitous fall monitoring at home via wireless sensor network and a wearable mote, Expert Syst. Appl. 39 (2012) 5566-5575.

[8] M. Spadacini, S. Savazzi, M. Nicoli, Wireless home automation networks for indoor surveillance. technologies and experiments, EURASIP J. Wirel. Commun. Netw. (2014) (Paper number: 6).

[9] M.I. Martinez-Garrido, S. Aparicio, R. Fort, J.J. Anaya, M.A.G. Izquierdo, Effect of solar radiation and humidity on the inner core of walls in historic buildings, Constr. Build. Mater. 51 (2014) 383394

[10] Z. Liu, Y. Yu, G. Liu, J. Wang, X. Mao, Design of a wireless measurement system based on WSNs for large bridges, Measurement 50 (2014) 324-330.

[11] M.I.M. Rawi, A. Al-Anbuky, Wireless sensor networks and human comfort index, 2nd International Conference on Ambient Systems, Networks and Technologies (ANT), Niagara Falls, Canada, Sep 19-21, 2011, Pers. Ubiquit. Comput. 17 (5) (2013) 999-1011.

[12] H. Wu, M. Corr, M. Pozzi, D. Zonta, P. Zanon, M. Veriotti, L. Mottola, G.P. Picco, A.L. Murphy, S. Guna, Long term wireless ambient monitoring of heritage buildings, Proceedings of SPIE, ISSN 0277 786X, 04/2010, Actas de conferencia Sensors and Smart Structures 
Technologies for Civil, Mechanical, and Aerospace Systems (2010) ISBN 9780819480620, 7647(1), 76470K-76470K-12.

[13] I.M. Tolentino, R.S. Juson, B.U. Tan, M.R. Talampas, Design, Development, and Evaluation of a Simple Wireless Sensor Network for Indoor Microclimate Monitoring, IEEE Region 10 Conference on TENCON, Fukuoka, Japan, Nov 21-24 (2010), Editors: T. Okado, K. Araki, H. Nishino.

[14] D.M. Freire-Lista, M.I. Martínez-Garrido, R. Fort, Monitoring Techniques for Microclimatic Analysis in Cultural and Natural heritage for Decay Evaluation, 11th International Conference on Non-Destructive Investigations and Microanalysis for the Diagnostics and Conservation of Cultural and Environmental Heritage ART'14, Madrid, Spain, 11-13 June (2014) ISBN: 978-84697-0522-3 IND 114.

[15] M.I. Martínez-Garrido, R. Fort, Wireless sensor networks for conservation monitoring in archaeological sites" YOCOCU 2014 Youth in Conservation of Cultural Heritage, Baku-Agsu, Azerbaijan, 28-30 May (2014).

[16] M.J. Varas-Muriel, R. Fort, M.I. Martínez-Garrido, A. Zornoza-Indart, P. Lopez-Arce, Fluctuations in the indoor environment in Spanish rural churches and their effects on heritage conservation: hygrothermal and $\mathrm{CO}_{2}$ conditions monitoring, Build. Environ. 82 (2014) 97-109.

[17] B. Krupinska, R. Van Grieken, K. De Wael, Air quality monitoring in museum for preventive conservation: results of a three-year study in the Plantin-Moretus Museum in Antwerp, Belgium, Microchem. J. 110 (2013) 350-360

[18] A. Fernandez-Navajas, P. Merello, P. Beltran, F.J. García-Diego, Multivariate thermo-hygrometric characterisation of the archaeological site of Plaza de l'Almoina (Valencia, Spain) for preventive conservation, Sensors 13 (8) (2013) 9729-9746.

[19] O. Allegretti, M. De Vincenzi, L. Uzielli, P. Dionisi-Vici, Long-term hygromechanical monitoring of Wooden Objects of Art (WOA): tool for preventive conservation, J. Cultural Heritage 14 (3) (2013) E161-E164.

[20] Smartmote Monitoring \& Testing. Available online: www. smartmote.de (accessed on 16/07/2014)

[21] Wireless networking in the developing world, Third Edition (Feb. 2013) ISBN-13: 978-1484039359 Available online: http://wndw. net/download/WNDW_Standard.pdf (accessed on 18/07/2014).

[22] Y.B. Liang, S.F. Midkiff, Multipath Fresnel Zone Routing for Wireless Ad Hoc Networks, 1-4, IEEE Wireless Communications and Networking Conference, New Orleans, LA, 2005. pp. 1958-1963.
[23] Wireless Sensor Network System Description Report D3.2 Smart wireless sensor network platform, Available online: http://www. smoohs.eu/ (accessed on 16/07/2014).

[24] M.I. Martínez-Garrido, R. Fort, Sensing technologies for monitoring and conservation of cultural heritage: wireless detection of decay factor, Science, Technology and Cultural Heritage, CRC Press, 2014, ISBN 978-1-138-02744-2, pp. 495-501.

[25] D. Bucur, G. Iacca, G. Squillero, A. Tonda, The impact of topology on energy consumption for collection tree protocols: an experimental assessment through evolutionary computation, Appl. Soft Comput. 16 (2014) 210-222

[26] O. Gnawali, R. Fonseca, K. Jamieson, M. Kazandjieva, D. Moss, P. Levis, CTP: an efficient, robust, and reliable collection tree protocol for wireless sensor networks, ACM Trans. Sensor Netw. 10 (1) (2013) (Paper number: 16)

[27] SHT25 - Digital Humidity Sensor (RH\&T), Available online: http:// www.sensirion.com/en/products/humidity-temperature/humiditysensor-sht25/ (accessed on 16/07/2014).

[28] IEEE std. 802.15.4 - 2006: Wireless Medium Access Control (MAC) and Physical Layer (PHY) specifications for Low Rate Wireless Personal Area Networks (LR-WPANs), Available online: http://standards.ieee.org/getieee802/download/802.15.4-2006.pdf (accessed on 16/07/2014).

[29] G. Blumrosen, A. Luttwak, Human body parts tracking and kinematic features assessment based on RSSI and inertial sensor measurements, Sensors 13 (9) (2013) 11289-11313.

[30] CC2520 Second generation $2.4 \mathrm{GHz}$ ZigBee/IEEE 802.15.4 RF transceiver, Available online: http://www.ti.com/ (accessed on 16/ 07/2014)

[31] M.J. Varas-Muriel, M.I. Martinez-Garrido, R. Fort, Monitoring the thermal-hygrometric conditions induced by traditional heating systems in a historic Spanish church (12th-16th C), Energy Build. 75 (2014) 119-132.

[32] I. Álvarez Calvo, Pérdidas de inserción en diferentes tipos de materiales y árboles, Escuela Politécnica Superior de Ingeniería de Telecomunicación, Universidad Autónoma de Madrid (UAM), Abril 2013, Available online: http://arantxa.ii.uam.es/ jms/pfcsteleco/ lecturas/20130423IgnacioAlvarezCalvo.pdf (accessed on 25/07/ 2014)

[33] M.I. Martínez Garrido; R. Fort, Wireless monitoring to detect decay factors in natural heritage scenarios in Spain: a case study at Lanzarote. Sensing the Past. Geoscience and Sensing Technologies for cultural heritage. Springer, 2015. 